\title{
In vivo effects of glucosamine on insulin secretion and insulin sensitivity in the rat: Possible relevance to the maladaptive responses to chronic hyperglycaemia
}

\author{
A. Giaccari ${ }^{1,2}$, L. Morviducci ${ }^{2}$, D. Zorretta ${ }^{1}$, P. Sbraccia ${ }^{1,2}$, F. Leonetti ${ }^{2}$, S. Caiola ${ }^{1}$, A. Buongiorno ${ }^{1}$, R. C. Bonadonna ${ }^{3}$, \\ G. Tamburrano ${ }^{2}$ \\ ${ }^{1}$ Laboratory of Clinical Biochemistry, Istituto Superiore di Sanità, Rome, Italy \\ ${ }^{2}$ Division of Endocrinology, II Clinica Medica, Policlinico Umberto I, Rome, Italy \\ ${ }^{3}$ Division of Metabolic Diseases, University of Verona, Verona, Italy
}

Summary We tested the hypothesis that glucosamine, a putative activator of glucose toxicity in vitro through acceleration of the hexosamine pathway, may determine in vivo the two key features of glucose toxicity in diabetes, namely, peripheral insulin resistance and decreased insulin secretion. Two groups of awake rats were studied either with intraarterial administration of glucosamine $\left(5 \mu \mathrm{mol} \cdot \mathrm{kg}^{-1}\right.$. $\mathrm{min}^{-1}$ ) or saline. Insulin secretion was determined after arginine, glucose (hyperglycaemic clamp), and arginine/glucose infusions, while insulin-mediated glucose metabolism was assessed by the euglycaemic hyperinsulinaemic clamp in combination with [3$\left.{ }^{3} \mathrm{H}\right]$-glucose infusion. Glucosamine had no effects on arginine-induced insulin secretion both at euglycaemia and hyperglycaemia, but significantly (40$50 \%$ ) impaired glucose-induced insulin secretion (both first and second phases). During euglycaemic hyperinsulinaemic clamp studies, glucosamine decreased glucose uptake by $\sim 30 \%$, affecting glycolysis (estimated from ${ }^{3} \mathrm{H}_{2} \mathrm{O}$ rate of appearance) and muscle glycogen synthesis (calculated from accumulation of $\left[{ }^{3} \mathrm{H}\right]$-glucosyl units in muscle glycogen) to a similar extent. Muscle glucose 6-phosphate concentration was markedly reduced in the glucosamine-infused rats, suggesting an impairment in glucose transport/phosphorylation. Therefore, an increase in hexosamine metabolism in vivo: 1) inhibits glucose-induced insulin secretion, and 2) reduces insulin stimulation of both glycolysis and glycogen synthesis, thereby mimicking in normal rats the major alterations due to glucose toxicity in diabetes. [Diabetologia (1995) 38: 518-524]

Key words Glucosamine, insulin resistance, insulin secretion, glucose toxicity, glucose clamp.
It is commonly believed that, by chronically lowering blood glucose, peripheral insulin action is improved in human diabetes [1]. Furthermore, in non-insulindependent diabetes, insulin secretion is also ameliorated by any treatment modality which improves glucose control [1]. In the rat made diabetic both insulin secretion and insulin action deteriorate, but stay nor-

Received: 12 August 1994 and in revised form 4 November 1994

Corresponding author: Dr. A. Giaccari, Cattedra di Endocrinologia, II Clinica Medica, Policlinico Umberto I, I-00161, Rome, Italy

Abbreviations: GFAT, Glutamine:fructose 6-phosphate amidotransferase; UDP-N-acetylglucosamine, uridine-diphospho-N-acetylglucosamine. mal if hyperglycaemia is prevented through the administration of phloridzin, a glucosuric agent [2-4]. These observations have led to the concept of 'glucose toxicity', according to which hyperglycaemia, by blunting beta-cell secretion of and cellular response to insulin, establishes a self-perpetuating vicious cycle of great pathogenic relevance in diabetes mellitus [1].

In an outstanding series of papers [5-9], Stephen Marshall and his colleagues have shown that, in primary cultured rat adipocytes, an increase in hexosamine synthesis, a quantitatively minor but ubiquitous pathway of intracellular glucose metabolism, is responsible for glucose-induced reduction in insulinmediated glucose metabolism through desensitization of the glucose transport system. In fact glucose, after being phosphorylated to glucose 6-phosphate, 
can follow two major metabolic pathways, i. e., glycogen synthesis (through glucose 1-phosphate) and glycolysis (through fructose 6-phosphate) [5-9]; a small fraction of fructose 6-phosphate, however, is not channelled to glycolysis, but converted to glucosamine 6-phosphate by the enzyme glutamine:fructose 6-phosphate amidotransferase (GFAT), the first and the rate-limiting enzyme of the hexosamine synthetic pathway [8], which employs glutamine as an amine donor. Glucosamine 6-phosphate then undergoes acetylation to $\mathrm{N}$-acetylglucosamine 6-phosphate, and is subsequently converted to UDP-N-acetylglucosamine to form sialic acids, gangliosides, glycoproteins, some glycolipids, and proteoglycans [10]. In primary cultured adipocytes, azaserine, a GFAT inhibitor, prevents the glucose deleterious effect on its own uptake, whereas glucosamine, which increases hexosamine metabolism, causes desensitization of glucose transport to insulin [5-9]. Glucosamine is a useful tool with which to increase hexosamine metabolism because it is transported inside the cell by glucose transporters and readily phosphorylated to glucosamine 6-phosphate by hexokinase, thereby bypassing the rate-limiting step of GFAT [5-9]. Thus, according to Marshall et al., glucose toxicity in insulin sensitive cells is mediated by some yet unidentified compound(s) downstream to glucosamine 6-phosphate, which triggers a desensitization mechanism and leads to a loss in the ability of insulin to stimulate the translocation of glucose transporters to the plasma membrane.

Glucosamine may also play a role in glucose-induced impairment of beta-cell function. An increase in beta-cell hexosamine biosynthesis elicited by a high ambient glucose concentration would give rise to glucosamine 6-phosphate and, after hydrolysis, to glucosamine. Glucosamine itself can inhibit pancreatic glucokinase, the putative glucose sensor of the beta cell [11], and reduces glucose-induced insulin secretion in isolated pancreatic islets [12]. Alternatively, it has been reported that acceleration of hexosamine metabolism in the beta cell may lead to a generalized desensitization to insulin secretagogues by depressing phosphoinositide hydrolysis. Pre-exposure of rat islets to high glucose completely abolishes the deleterious effects of glucosamine on insulin secretion, presumably by maximally activating on its own the hexosamine synthesis pathway [11].

An increase in hexosamine metabolism, either secondary to the increased fructose 6-phosphate supply for GFAT reaction or to exogenously administered glucosamine, is therefore capable of reducing glucose metabolism and insulin secretion in vitro, mimicking glucose toxicity [1]. In order to verify this hypothesis in vivo, we examined the effects of glucosamine infusion on insulin secretion and insulin sensitivity during clamp studies in the awake rat. Our findings indicate that an increase in glucosamine supply decreases glucose (but not arginine) induced insulin secretion and impairs insulin-mediated glucose metabolism in skeletal muscle.

\section{Materials and methods}

Animal preparation. Male Sprague-Dawley rats (Charles River Laboratories, Lecco, Italy; body weight: $\sim 250 \mathrm{~g}$ ) were studied. The rats were given free access to food and water, were housed in individual cages in an air controlled room, and were subjected to a standard 12-h light/dark cycle.

Five to seven days before the experiment, all animals were anaesthetized with an intraperitoneal injection of pentobarbital $(50 \mathrm{mg} / \mathrm{kg}$ body weight), and indwelling catheters were inserted into the right jugular vein and in the left carotid artery. The venous catheter was extended to the level of the right atrium, and the arterial catheter was advanced to the level of the aortic arch. Both catheters were filled with heparin/polyvinilpyrrolidone solution, sealed, tunnelled subcutaneously around the side of the neck and exteriorized through a skin incision [13-18].

Experimental protocol. All studies were conducted in the morning after a 24-h fast. Throughout the studies the rats were awake, and allowed to move freely within the confines of a large cage, with the connecting tubing suspended overhead. The venous catheter was used for blood withdrawal and the arterial catheter for the infusion of the test substances. To prevent intravascular volume depletion and anaemia, fresh whole blood obtained by heart puncture from fasting littermates of the test animal was administered at a constant rate designed to quantitatively replace the total blood loss during the study [14-18]. All rats $(n=24)$ were randomly assigned to the Glucosamine group $(n=12)$ or the Saline control group $(n=12)$. A priming injection $(180 \mu \mathrm{mol} / \mathrm{kg}$ over a 2 -min period) followed by a constant $\left(5 \mu \mathrm{mol} \cdot \mathrm{kg}^{-1} \cdot \mathrm{min}^{-1}\right)$ glucosamine infusion was started $10 \mathrm{~min}$ prior to the clamp studies and continued throughout the study. Crystalline D-glucosamine was purchased from Sigma - Aldrich (Milan, Italy) and was diluted in saline with a final concentration of $\sim 40 \mathrm{nmol} / 1$ (according to rat body weight). Equal volumes of saline were infused during the saline control studies. The rate of glucosamine infusion was chosen on the basis of the present estimates of the rate of fructose 6-phosphate conversion to glucosamine 6phosphate $(-0.8-1 \%$ of overall glucose metabolism, that is $-2-2.7 \mu \mathrm{mol} \cdot \mathrm{kg}^{-1} \cdot \mathrm{min}^{-1}$ during the insulin clamp studies, [5]) in order to increase by $2-3$ fold the rate of glucosamine $6-$ phosphate generation. The study protocol followed the guidelines approved by the Animal Care Committee of the Istituto Superiore di Sanità.

Euglycaemic clamp study. Insulin-mediated whole body glucose uptake was measured using the euglycaemic clamp in combination with $\left[3-{ }^{3} \mathrm{H}\right]$-glucose infusion, as previously described [14-18]. Briefly, both the glucosamine-infused rats $(n=6)$ and the saline-infused rats $(n=6)$ received a primel continuous infusion of insulin (Bio-Insulin R, Laboratori Guidotti, Pisa, Italy) at $20 \mathrm{mU} \cdot \mathrm{kg}^{-1} \cdot \mathrm{min}^{-1}$ for $2 \mathrm{~h}$. A variable infusion of $25 \%$ glucose solution was started at time 0 and adjusted in order to clamp the plasma glucose concentration at approximately $5.6 \mathrm{mmol} / 1$. A prime/continuous $(\sim 0.4 \mu \mathrm{Ci} / \mathrm{min})$ infusion of $\left[3-{ }^{3} \mathrm{H}\right]$-glucose (Du Pont - New England Nuclear, Milan, Italy) was initiated at time zero and continued throughout the study [14-18]. Plasma samples for determination of $\left[3-{ }^{3} \mathrm{H}\right]-$ glucose and tritiated water specific activities were obtained at 
5-10 min intervals throughout the insulin clamp study. Plasma samples for determination of plasma insulin concentration were obtained at time $-20,0,60,90,120$ min during the study. At the end of the 120-min study rats were injected intravenously with pentobarbital $(60 \mathrm{mg} / \mathrm{kg}$ body weight), the abdomen was quickly opened, the rectus abdominal muscle was freezeclamped in situ and then the hindlimb muscle tissue was freeze-clamped with aluminium tongs pre-cooled in liquid nitrogen. All tissue samples were kept frozen at $-80^{\circ} \mathrm{C}$ for subsequent analysis.

Glycogen formation in vivo. Muscle glycogen synthesis was quantitated by two independent means: first, by determining the increment in cold glycogen concentration above fasting levels, and second, by measuring the incorporation of $\left[3-{ }^{3} \mathrm{H}\right]-$ glucose counts into glycogen [17]. Glycogen concentrations were determined following digestion with amyloglucosidase as previously described [17]. The intraassay and the interassay coefficients of variation were 8.4 and $9.2 \%$ (at $250 \mathrm{mg} / 100 \mathrm{~g}$ wet tissue weight) when a muscle homogenate was assayed as multiple aliquots. Aliquots of the tissue homogenate $(200 \mu \mathrm{l})$ were employed to determine the amount of tritium label in glycogen. Glycogen was precipitated by washing in 10 volumes of absolute ethanol and by incubating for $1 \mathrm{~h}$ at $-20^{\circ} \mathrm{C}$. The procedure was repeated three times and then the precipitate was collected, dried down and dissolved in water before scintillation counting. The recovery of free $\left[3-{ }^{3} \mathrm{H}\right]$-glucose, added to test the procedure, was less than $1 \%$ of the free glucose radioactivity added to the homogenate in each assay.

Whole body glycolytic flux in vivo. Aliquots of plasma were precipitated with $\mathrm{Ba}(\mathrm{OH})_{2}$ and $\mathrm{ZnSO}_{4}$ and centrifuged. Plasma tritiated water specific activity was determined by liquid scintillation counting of the protein-free supernatant (Somogyi filtrate) before and after evaporation to dryness. Because tritium on the $\mathrm{C}-3$ position of glucose is lost to water during glycolysis, it can be assumed that plasma tritium is present either in tritiated water or $\left[3-{ }^{3} \mathrm{H}\right]$-glucose [17]. Plasma water was assumed to be $93 \%$ of the total plasma volume and total body water mass was assumed to be $65 \%$ of the body mass [17].

Calculations. Data for total body glucose uptake and suppression of bepatic glucose production represent the mean values during the last $30 \mathrm{~min}$. The hepatic glucose production was calculated as the difference between the tracer derived rate of appearance and the infusion rate of glucose. Total body glucose disposal was calculated by adding the rate of residual hepatic glucose production during the last $30 \mathrm{~min}$ of each insulin clamp to the glucose infusion rate during the same $30-\mathrm{min}$ time period. The rate of net glycogen synthesis was calculated by dividing the amount of $\left[3{ }^{3} \mathrm{H}\right]$-glucose incorporated in glycogen (dpm per gram of muscle tissue) by the time-weighed mean plasma $\left[3-{ }^{3} \mathrm{H}\right]$-glucose specific activity $(\mathrm{dpm} / \mathrm{mg}$ glucose). In each rat three separate determinations on hindlimb muscle tissue were averaged in order to approximate the mean whole body muscle glycogen synthesis. Hindlimb muscles were selected for glycogen assay because of their mixed composition of fiber types. The whole body glycolytic rate was calculated from the increment per min in plasma ${ }^{3} \mathrm{H}_{2} \mathrm{O}$ radioactivity from 60 to 120 min multiplied by the body water space and divided by the $\left[3-{ }^{3} \mathrm{H}\right]$-glucose specific activity [1417].

Arginine/hyperglycaemic clamp study. In both glucosamine-infused rats $(n=6)$ and saline-infused rats $(n=6)$ blood was obtained at time $-20,-10$ (before glucosamine/saline infusions) and $0 \mathrm{~min}$ for the determination of plasma glucose and insulin concentrations. At time 0 a prime/continuous infusion of $\mathrm{L}-\mathrm{ar}$ ginine (Sigma - Aldrich) solution $(300 \mathrm{mg} / \mathrm{ml})$ was administered from time $0 \mathrm{~min}$ to time $30 \mathrm{~min}$ to acutely raise and maintain the plasma arginine concentration at approximately $2 \mathrm{mmol} / \mathrm{l}$. The prime was administered at a rate of $280 \mu \mathrm{mol} /$ min from 0 to $2 \mathrm{~min}$ and the continuous infusion was administered at $36 \mu \mathrm{mol} / \mathrm{min}$ from 2 to $30 \mathrm{~min}$. Blood for the determination of plasma glucose and insulin concentrations was obtained at time $2,4,6,8,10,20$, and 30 min after starting the arginine infusion. Between 30 and $75 \mathrm{~min}$ a constant saline infusion $(20 \mu \mathrm{l} / \mathrm{min})$ was administered to keep the venous and arterial catheters patent. Plasma glucose was determined again at time 75 and at time $80 \mathrm{~min}$ a priming infusion of $25 \%$ glucose was administered to acutely raise the plasma glucose concentration to $11.5 \mathrm{mmol} / \mathrm{l}$. The plasma glucose concentration was subsequently held constant at this hyperglycaemic plateau until time $170 \mathrm{~min}$ by the adjustment of a variable glucose infusion based upon a negative feedback principle (hyperglycaemic clamp) [19]. Plasma samples for the determinations of glucose and insulin were obtained at 2-min intervals between time 80 and $90 \mathrm{~min}$ and at 10-min intervals thereafter until $140 \mathrm{~min}$. From 140 to $170 \mathrm{~min}$ a prime/continuous infusion of arginine was again administered as described above. Plasma samples for the glucose and insulin were again obtained at 2-min intervals between time 140 and $150 \mathrm{~min}$ and at 10-min intervals thereafter until $170 \mathrm{~min}$ [4].

Calculations. Plasma insulin concentrations are presented in Figure 4 as areas under the curves (AUCs) of insulin concentration during the arginine (panel A) glucose (panel B) and arginine/glucose (panel C) stimuli. First phase insulin secretion was calculated from the blood samples collected in the first $10 \mathrm{~min}$ after each stimulus. Second phases were calculated from the subsequent samples ( 20 to $50 \mathrm{~min}$ after first phases).

Analytical procedures. Plasma glucose was measured by the glucose oxidase method (Glucose Analyzer II; Beckman Instruments, Milan, Italy) and plasma insulin by radioimmunoassay (RIA) using rat insulin standards (Rat insulin RIA kit highly sensitive; Novo - Nordisk, Bagsvaerd, Denmark). Glucose 6-phosphate was measured spectrophotometrically in rectus abdominal muscle tissue as described by Michal [20]. This muscle was selected because it can be easily freeze-clamped in situ (i.e., prior to its removal). Muscle contractions occurring during excision alter glucose 6-phosphate concentration [14]. Plasma $\left[3-{ }^{3} \mathrm{H}\right]$-glucose radioactivity was measured on the supernatants of barium hydroxide-zinc sulphate precipitates (Somogyi procedure) of plasma samples after evaporation to dryness to eliminate tritiated water [17].

\section{Statistical analysis}

All values are presented as mean \pm SEM. Differences between groups were determined using the Student's $t$-test for unpaired data.

\section{Results}

General characteristics of the animals (Table 1). There were no differences in the mean body weights between glucosamine- and saline-infused rats. Both fasting plasma insulin and glucose concentrations 
Table 1. General characteristics of the animals

\begin{tabular}{lll}
\hline Group & Glucosamine & Saline \\
\hline $\begin{array}{l}\text { Body weight }(\mathrm{g}) \\
\begin{array}{l}\text { Fasting plasma glucose } \\
\text { (mmol/1) }\end{array}\end{array}$ & $252 \pm 11$ & $247 \pm 5$ \\
$\begin{array}{l}\text { Fasting plasma insulin } \\
\text { (pmol/1) }\end{array}$ & $6.5 \pm 0.5$ & $6.6 \pm 0.6$ \\
$\begin{array}{l}\text { Steady-state plasma glucose } \\
\text { (mmol/1) }\end{array}$ & $75 \pm 12$ & $58 \pm 10$ \\
$\begin{array}{l}\text { Steady-state plasma insulin } \\
\text { (pmol/l) }\end{array}$ & $5.52 \pm 0.10$ & $5.57 \pm 0.09$ \\
\hline
\end{tabular}

measured before the glucosamine/saline infusions were similar in the two groups.

Insulin clamp study (Figs. 1 and 2). Steady-state plasma glucose and insulin concentrations during the insulin clamp studies were similar in the two groups (Table 1). The coefficients of variation in plasma glucose levels were 4.5 and $4.7 \%$ in glucosamine- and saline-infused rats, respectively.

Hepatic glucose production was completely suppressed in both groups $(7.8 \pm 5.3$ vs $4.6 \pm 4.3 \mu \mathrm{mol}$. $\mathrm{kg}^{-1} \cdot \mathrm{min}^{-1}$ in glucosamine- and saline-infused rats, respectively), with no statistical differences between the two groups. Tissue glucose uptake (Fig.1A) was significantly decreased in glucosamine-infused compared to saline-infused control rats $(276 \pm 15$ vs $210 \pm 12 \mu \mathrm{mol} \cdot \mathrm{kg}^{-1} \cdot \mathrm{min}^{-1}$, respectively, $p<0.003$ ), as well as the glucose infusion rates needed to maintain euglycaemia $\left(272 \pm 19\right.$ vs $203 \pm 12 \mu \mathrm{mol} \cdot \mathrm{kg}^{-1}$. $\left.\mathrm{min}^{-1}\right)$. After phosphorylation, glucose can enter either of two major metabolic pathways, glycolysis and glycogen synthesis. When the contributions of these two major fates of intracellular glucose were examined in the glucosamine-infused rats, both were found to be significantly reduced. Net muscle glycogen synthesis, measured either as $\left[3-{ }^{3} \mathrm{H}\right]$-glucosyles accumulated in glycogen (Fig. 1C) or as difference of glycogen concentration from the fasting state (data not shown) was consistently reduced by $-30 \%$ $\left(126 \pm 8\right.$ vs $176 \pm 10 \mu \mathrm{mol} \cdot \mathrm{kg}^{-1} \cdot \mathrm{min}^{-1}$ in glucosamine- and saline-infused groups, respectively, $p<0.002$ ). Whole body glycolysis (Fig. 1B) was also reduced in glucosamine-infused rats $(69.8 \pm 4.3$ vs $\left.97.3 \pm 7.2 \mu \mathrm{mol} \cdot \mathrm{kg}^{-1} \cdot \mathrm{min}^{-1}, p<0.01\right)$. The defects found in skeletal muscle glycogen synthesis and whole body glycolysis could quantitatively account for the entire difference in overall glucose uptake between glucosamine- and saline-infused rats. Muscle glucose 6-phosphate (Fig.2B), the first intracellular product of glucose metabolism (prior to glycogen synthesis or glycolysis), was markedly decreased in glucosamine-infused rats $(0.30 \pm 0.08$ vs $0.82 \pm$ $0.17 \mu \mathrm{mol} / \mathrm{g}$ wet weight in glucosamine- and saline-infused groups, respectively, $p<0.01$ ).

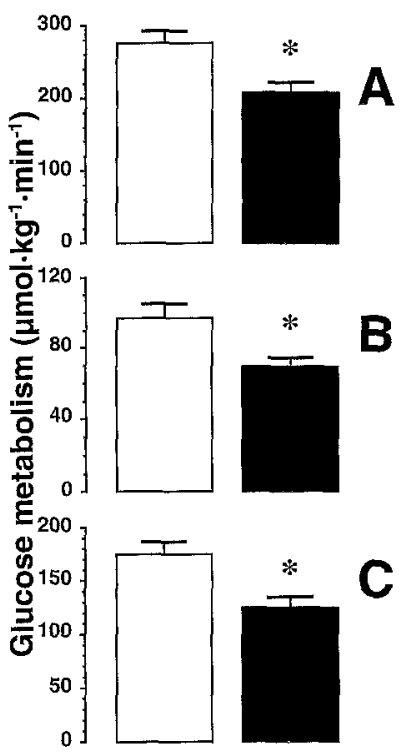

Fig.1A-C. Total glucose metabolism (A), whole body glycolysis (B) and muscle glycogen synthesis (C) during the hyperinsulinaemic, euglycaemic clamp studies in saline-infused ( $\square$ ), and glucosamine-infused ( $\square$ rats. ${ }^{*} p<0.01$ or less

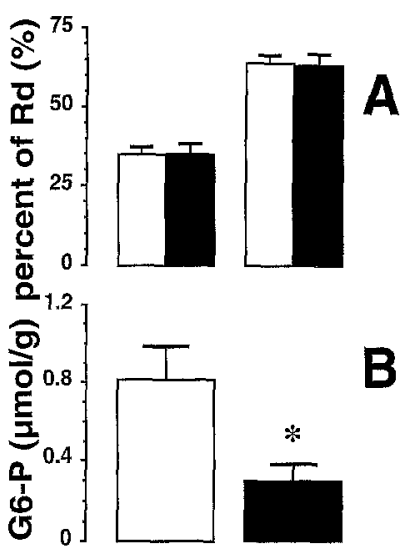

Fig. 2 A Relative contribution of whole-body glycolysis (left) and muscle glycogen synthesis (right) in saline-infused ( $\square$ ), and glucosamine-infused ( $\square$ ) rats. B Glucose 6-phosphate (G6-P) concentrations in rectus abdomini freeze-clamped in situ at the end of the euglycaemic clamp studies in saline-infused $(\square)$, and glucosamine-infused ( $\square$ ) rats. *p<0.01

Insulin secretion study (Figs. 3 and 4). After $24 \mathrm{~h}$ of fasting, plasma insulin and glucose concentrations were identical in the two groups. At time 0 (i.e., $10 \mathrm{~min}$ after starting the glucosamine/saline infusions) both plasma insulin and glucose concentrations were unchanged in both groups (Fig.3). Two minutes after starting the arginine infusion, plasma insulin peaked to $2.69 \pm 0.46 \mathrm{nmol} / \mathrm{l}$ in the glucosamine-infused group, and to $3.28 \pm 0.42 \mathrm{nmol} / \mathrm{l}$ in the saline-infused control group ( $p=\mathrm{NS}$ ), (Fig. 3A). Neither first nor second phase of arginine-stimulated insulin secretion were altered by glucosamine infusion (Fig. 4A). 

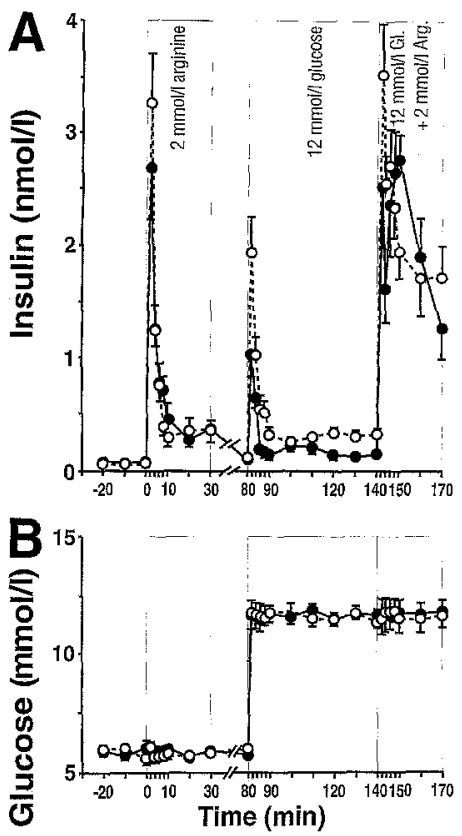

Fig.3A-B. Time course insulin (A) and glucose (B) concentrations during the insulin secretion studies in saline-infused (O), and glucosamine-infused (O) rats. Arginine concentration was acutely raised to $\sim 2 \mathrm{mmol} / 1$ for $30 \mathrm{~min}(0-30 \mathrm{~min})$. After $50 \mathrm{~min}$, a hyperglycaemic clamp (plasma glucose $-12 \mathrm{mmol} / \mathrm{l})$ was performed ( $80-170 \mathrm{~min})$. At time 140 , arginine concentration was again raised to $\sim 2 \mathrm{mmol} / \mathrm{l}$ for $30 \mathrm{~min}$

At time $80 \mathrm{~min}$ (i.e., $50 \mathrm{~min}$ after interrupting arginine, and at time 0 of the hyperglycaemic clamp), both plasma insulin and glucose were back to fasting levels (Fig.3). At time 82 min (i.e., immediately after the glucose bolus of the hyperglycaemic clamp) plasma insulin peaked at $1.02 \pm 0.19 \mathrm{nmol} / 1$ in the glucosamine-infused group, and at $1.95 \pm 0.30 \mathrm{nmol} / 1$ in the saline-infused control group $(p<0.02)$ (Fig.3A). Both first and second phases of glucose-stimulated insulin secretion were reduced by glucosamine infusion (Fig. 4B). At time $142 \mathrm{~min}$ (i.e., immediately after the arginine bolus during the hyperglycaemic clamp) plasma insulin peaked at $2.51 \pm 0.53 \mathrm{nmol} / \mathrm{l}$ in the glucosamine-infused group, and at $3.54 \pm 0.44 \mathrm{nmol} / 1$ in the saline-infused control group ( $p=$ NS). Neither the first nor second phase of insulin secretion were altered by glucosamine infusion (Fig. 4C).

\section{Discussion}

The present study examines the effects of an increase in glucosamine metabolism on beta-cell function and insulin-mediated glucose metabolism in the conscious intact rat. Glucosamine infusion effectively decreased insulin stimulation of both muscle glycogen synthesis and whole body glycolysis, which together accounted for virtually the entire reduction in whole body glucose metabolism. When expressed as per-
A. Giaccari et al.: Glucosamine effects on insulin secretion and action

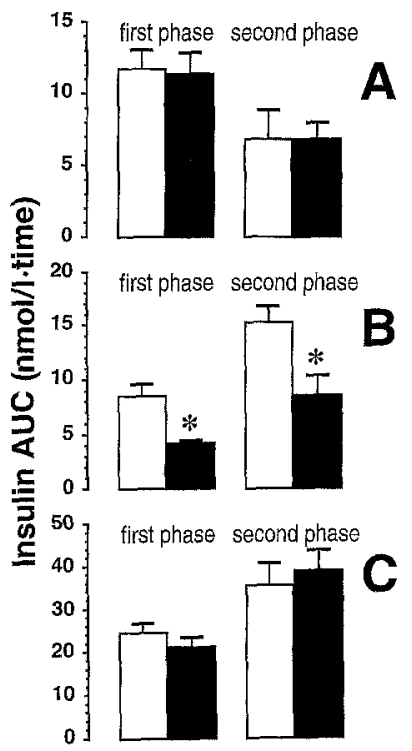

Fig. 4A-C. Area under the curve (AUC) of insulin concentration during the arginine load (A), the hyperglycaemic clamp (B) and the arginine + glucose load (C) in saline-infused ( $\square$ ), and glucosamine-infused $(\boldsymbol{Q})$ rats. Units for ordinates are $\mathrm{nmol} \cdot 10 \mathrm{~min} \cdot 1^{-1}$ for first phases, $\mathrm{nmol} \cdot 20 \mathrm{~min} \cdot \mathrm{I}^{-1}$ for $\mathrm{sec}$ ond phases of panels $\mathrm{A}$ and $\mathrm{C}$, and $\mathrm{nmol} \cdot 50 \mathrm{~min} \cdot \mathrm{l}^{-1}$ for second phase of insulin secretion of panel $\mathrm{B}$. Both first phase (first $10 \mathrm{~min}$ of each challenge) and second phase (following 30-50 $\mathrm{min}$ ) were inhibited by glucosamine infusion only during the hyperglycaemic clamp ( ${ }^{*} p<0.01$ or less)

cent of the saline control results, the impairments in glycogen synthesis and glycolysis were similar $(\sim 30 \%)$, thus, the relative contribution of these two major pathways to overall glucose metabolism remained unaffected (Fig. 2A). This result is equally compatible with either glucosamine inhibiting a ratedetermining step proximal to glycogen synthesis and glycolysis (i.e., glucose transport and/or phosphorylation) or glucosamine acting separately, but with similar effectiveness, on both glycogen synthesis and glycolysis. Application of the crossover theorem to muscle glucose 6-phosphate concentrations may help to solve this conundrum. In the former case, since glucose transport/phosphorylation is inhibited, but glycogen synthesis and glycolysis are normally active, muscle glucose 6-phosphate levels must fall. In the latter case, since glucose transport/phosphorylation is operating normally, but glycogen synthesis and glycolysis are impaired, muscle glucose 6-phosphate is expected to rise. In the glucosamine-infused rats muscle glucose 6-phosphate was reduced by $\sim 63 \%$ (Fig. 2B), thereby indicating that glucosamine restrains insulin-mediated glucose metabolism by acting primarily on glucose transport and/or phosphorylation. Furthermore, the greater decrease in substrate (i.e., glucose 6-phosphate) concentration $(-63 \%)$ than in fluxes $(-30 \%)$ suggests that during glucosamine infusion the fractional activities of glycogen synthesis and glycolysis may actually be in- 
creased. These results are consistent with several previous studies performed in in vitro systems, in which glucosamine was shown to inhibit the rate of glucose transport and of glycogen synthesis, but to increase the activities of glycogen synthase and pyruvate kinase, two key enzymes in the glycogen synthesis and glycolysis pathways [21, 22].

We also assessed the influence of glucosamine on beta-cell function in vivo using two insulin secretagogues, arginine and glucose, alone and in combination. The rationale being, if glucosamine primarily acts by inhibiting glucokinase, the putative glucose sensor in the beta cell [23], it should conceivably affect the beta-cell response to glucose, but not to arginine. On the other hand, if glucosamine leads to a generalized desensitization of the beta cell, both glucose- and arginine-induced responses would be altered. Glucosamine infusion indeed depressed both first and second phase of insulin secretion in response to a square wave of hyperglycaemia, whereas beta-cell response to arginine was unaffected.

Both inhibitory and stimulatory effects of glucosamine on insulin secretion have been observed in studies conducted in isolated islets $[11,24,25]$. Stimulation of insulin secretion by glucosamine, however, is short-lasting and is followed by desensitization of the islets to both glucose and non-glucose secretagogues (e.g., alpha-ketoisocaproate). These in vitro observations seem at variance with our in vivo findings, which show an intact beta-cell response to a non-glucose secretagogue such as arginine. Some key differences between the in vitro experimental conditions and our in vivo studies may help to explain these discrepancies. Zawalich and Zawalich [11] pre-exposed islets to very high $(5-10 \mathrm{mmol} / \mathrm{l})$ glucosamine concentrations and subsequently stimulated beta cells with glucose and alpha-ketoisocaproate after removing glucosamine from the incubation medium. Under their experimental conditions, glucosamine was largely metabolized, and the products of its metabolism were responsible for the subsequent non-specific inhibition of insulin release. In contrast, in our studies performed in vivo, islets were exposed to a low glucosamine dose in the presence of significant $(5-10 \mathrm{mmol} / \mathrm{l})$ glucose concentrations. Since glucose quickly equilibrates across the plasma membrane of the beta cells (but not of the insulin-sensitive cells), it can effectively prevent extensive phosphorylation of glucosamine by islet glucokinase. Hence, glucosamine inhibition of insulin secretion in our studies is more likely to be due to some direct effect of glucosamine per se than to be mediated by products of glucosamine metabolism. Thus, the results of our studies are consistent with the hypothesis that glucosamine in vivo affects the glucose sensing mechanism(s) (possibly glucokinase), thereby impairing the beta-cell response to glucose. Importantly, glucosamine seems to spare the insulin secreting machinery of the beta cell, because it leaves the beta-cell response to arginine intact.

The results obtained when glucosamine was infused during the euglycaemic clamps closely resemble the defects observed in the rat made diabetic with a $90 \%$ pancreatectomy [14]. In both situations insulin-mediated glucose metabolism (glycogen synthesis and glycolysis) is diminished by $30 \%$. However, in our glucosamine-infused rats muscle glucose 6-phosphate is decreased, indicating a primary defect in glucose transport/phosphorylation, whereas in diabetic rats it is normal; results which are not contradictory. Glucose toxicity (and accelerated hexosamine metabolism) primarily impairs glucose transport, whereas diabetes hits several steps of glucose metabolism, including glucose transport and glycogen synthase. The former defect would lead to a fall in glucose 6-phosphate, the latter to an increase; both together cancel each other in affecting muscle glucose 6-phosphate in diabetes. It is reasonable that glucosamine infusion duplicates only the glucose toxicity specific defect(s), and not the entire spectrum of lesions seen in diabetes.

As to the insulin secretion studies, glucosamine decreased the beta-cell response to glucose by $40-50 \%$. In the diabetic rat, glucose-induced insulin secretion is blunted up to approximately $70 \%$ [4], when normalized per pancreatic mass. This quantitative, but not qualitative, discrepancy might simply be due to between laboratory variability. On the other hand, as explained above, by choosing a low-dose glucosamine infusion, we may have tested only the direct effects of glucosamine, and not accelerated the entire hexosamine pathway in the beta cell. We may not rule out the possibility that hyperglycaemia causes an acceleration of all hexosamine, not only of glucosamine, production rates in the beta cell, leading to more profound and more generalized defects in insulin secretion, as reported in in vitro islets. Yet, even in this case, the disproportionately high arginine-induced insulin secretion observed in the diabetic rat in vivo remains unexplained. Thus, glucosamine under the experimental conditions employed in this study reproduces some, but not all, features of betacell dysfunction in diabetes. Further studies will be needed to ascertain whether this partial mimicry is due to the format of administration employed in this study, or is intrinsic to glucosamine.

In summary, we have provided evidence that acceleration of hexosamine metabolism by glucosamine infusion in vivo closely mimics the defects of insulin action on peripheral glucose metabolism, which can be attributed to glucose toxicity. Glucosamine infusion also can partially reproduce the defects of insulin secretion observed in diabetes and charged to glucose toxicity. The overall weight of this experimental evidence obtained in the conscious intact rat lends support to Marshall's proposal [5-9] that accelera- 
tion of hexosamine metabolism by hyperglycaemia plays an important role in causing the lesions ascribed to glucose toxicity. A perhaps unexpected corollary of these studies is that, by showing that glucosamine infusion can cause the two basic abnormalities of non-insulin-dependent diabetes, i.e., impaired insulin action and reduced insulin secretion, calling attention to the possibility that the hexosamine synthesis pathway may hide serious candidate genes for the aetiology of non-insulin-dependent diabetes.

Acknowledgements. The authors wish to thank Ms. F. Zorretta, Mr. G. Ricciardi and Mr. E. Maroccia for their excellent technical assistance and Ms. M. Olivieri Sangiacomo for expert secretarial assistance. This work was supported in part by grants from the Istituto Superiore di Sanità (Progetto Sindromi Ipoglicemiche, to A. B.) and from the Centro Internazionale Studi Diabete (to G. T.). A. G. is the recipient of a post-graduate Fellowship Award from the Juvenile Diabetes Foundation International (file number 393323 ).

\section{References}

1. Rossetti L, Giaccari A, DeFronzo RA (1990) Glucose toxicity. Diabetes Care 13:610-630

2. Blondel O, Bailbe D, Portha B (1990) Insulin resistance in rats with non-insulin-dependent diabetes induced by neonatal (5 days) streptozotocin: evidence for reversal following phlorizin treatment. Metabolism 39:787-793

3. Lisato G, Cusin I, Tiengo A, Del Prato S, Jeanrenaud B (1992) The contribution of hyperglycaemia and hypoinsulinaemia to the insulin resistance of streptozotocin-diabetic rats. Diabetologia 35:310-315

4. Rossetti L, Shulman GI, Zawalich W, DeFronzo RA (1987) Effect of chronic hyperglycemia on in vivo insulin secretion in partially pancreatectomized rats. J Clin Invest 80:10371044

5. Marshall S, Bacote V, Traxinger RR (1991) Discovery of a metabolic pathway mediating glucose-induced desensitization of the glucose transport system. Role of hexosamine biosynthesis in the induction of insulin resistance. $\mathrm{J}$ Biol Chem 266:4706-4712

6. Marshall S; Garvey WT, Traxinger RR (1991) New insights into the metabolic regulation of insulin action and insulin resistance: role of glucose and amino acids. FASEB J 5:3031-3036

7. Traxinger RR, Marshall S (1992) Insulin regulation of pyruvate kinase activity in isolated adipocytes. Crucial role of glucose and the hexosamine biosynthesis pathway in the expression of insulin action. J Biol Chem 267:9718-9723

8. Traxinger RR, Marshall S (1991) Coordinated regulation of glutamine:fructose-6-phosphate amidotransferase activity by insulin, glucose, and glutamine. Role of hexosamine biosynthesis in enzyme regulation. J Biol Chem 266:1014810154

9. Marshall S, Bacote V, Traxinger RR (1991) Complete inhibition of glucose-induced desensitization of the glucose transport system by inhibitors of mRNA synthesis. Evidence for rapid turnover of glutamine:fructose-6-phosphate amidotransferase. J Biol Chem 266:10155-10161
10. Kornfeld S, Kornfeld R, Neufeld EF, O'Brian PJ (1964) The feedback control of sugar nucleotide biosynthesis in liver. Proc Natl Acad Sci USA 52:371-379

11. Zawalich WS, Zawalich KC (1992) Glucosamine-induced desensitization of beta-cell responses: possible involvement of impaired information flow in the phosphoinositide cycle. Endocrinology 130:3135-3142

12. Malaisse WJ, Lea MA, Malaisse-Lagae F (1968) The effect of mannoheptulose on the phosphorylation of glucose and the secretion of insulin by islets of Langerhans. Metabolism 17:126-132

13. Smith D, Rossetti L, Ferrannini E, Johnson CM, Cobelli C, Toffolo G, Katz LD, DeFronzo RA (1987) In vivo glucose metabolism in the awake rat: tracer and insulin clamp studies. Metabolism 36:1176-1186

14. Rossetti L, Giaccari A (1990) Relative contribution of glycogen synthesis and glycolysis to insulin-mediated glucose uptake. A dose-response euglycemic clamp study in normal and diabetic rats. J Clin Invest 85:1785-1792

15. Rossetti L, Giaccari A, Klein-Robbenhaar E, Vogel LR (1990) Insulinomimetic properties of trace elements and characterization of their in vivo mode of action. Diabetes 39:1243-1250

16. Rossetti L, Frontoni S, Dimarchi R, DeFronzo RA, Giaccari A (1990) Metabolic effects of insulin-like growth factor-I in diabetic rats. Diabetes $40: 444-448$

17. Giaccari A, Rossetti L (1992) Predominant role of gluconeogenesis in the hepatic glycogen repletion of diabetic rats. J Clin Invest 89:36-45

18. Rossetti L, Farrace S, Choi SB, Giaccari A, Sloan L, Frontoni S, Katz MS (1993) Multiple metabolic effects of CGRP in conscious rats: role of glycogen synthase and phosphorylase. Am J Physiol 264:E1-E10

19. DeFronzo RA, Tobin I, Andres R (1979) Glucose clamp technique: a method for quantifying insulin secretion and resistance. Am J Physiol 237:E214-E223

20. Michal G (1985) Carbohydrates. In: Bergmeyer NU (ed) Methods of enzymatic analysis. Vol. VI, VCH Publishers, Weinheim, pp 191-198

21. Robinson KA, Sens DA, Buse MG (1993) Pre-exposure to glucosamine induces insulin resistance of glucose transport and glycogen synthesis in isolated rat skeletal muscles. Study of mechanisms in muscle and in rat-1 fibroblasts overexpressing the human insulin receptor. Diabetes 42:1333-1346

22. Crook ED, Daniels MC, Smith TM, McClain DA (1993) Regulation of insulin-stimulated glycogen synthase activity by overexpression of glutamine: fructose-6-phosphate amidotransferase in rat-1 fibroblasts. Diabetes 42:12891296

23. Malaisse WJ, Sener A, Herchuelz A, Hutton JC (1979) Insulin release: the fuel hypothesis. Metabolism 28:373-386

24. Lambert AE, Junod A, Stauffacher W, Jeanrenaud B, Renold AE (1969) Organ culture of fetal rat pancreas. I. Insulin release induced by caffeine and by sugars and some derivatives. Biochim Biophys Acta 184:529-539

25. Zawalich WS, Dye ES, Matschinsky FM (1979) Metabolism and insulin-relasing capabilities of glucosamine and $\mathrm{N}$-acetylglucosamine in isolated rat islets. Biochem $\mathrm{J}$ 180:145-152 